\section{Atopic dermatitis in adolescence}

\author{
Giampaolo Ricci, ${ }^{1}$ Federica Bellini, ${ }^{1}$ \\ Arianna Dondi, ${ }^{1,2}$ Annalisa Patrizi, ${ }^{2}$ \\ Andrea Pession' ${ }^{1}$ \\ ${ }^{1}$ Pediatric Unit, Department of \\ Gynecologic, Obstetric and Pediatric \\ Sciences; ${ }^{2}$ Dermatology Unit, Department \\ of Internal Medicine, Aging and \\ Nephrological Diseases, University \\ of Bologna, Italy
}

\section{Abstract}

Atopic dermatitis (AD) is a chronic inflammatory skin disorder that typically occurs during childhood especially in the first year of life, with a variable frequency from $10 \%$ to $30 \%$. Recent studies have shown that in Europe among $10-20 \%$ of children with AD suffer from this disorder also in adolescence. $\mathrm{AD}$ is a chronic inflammatory skin disease with a typical onset in the first years of life and with a 10$30 \%$ prevalence among young children. AD prevalence in adolescence has been estimated around $5-15 \%$ in European countries. AD persists from childhood through adolescence in around $40 \%$ of cases and some risk factors have been identified: female sex, sensitization to inhalant and food allergens, allergic asthma and/or rhinoconjunctivitis, the practice of certain jobs. During adolescence, AD mainly appears on the face and neck, often associated with overinfection by Malassezia, and on the palms and soles. $\mathrm{AD}$ persistence during adolescence is correlated with psychological diseases such as anxiety; moreover, adolescents affected by $\mathrm{AD}$ might have problems in the relationship with their peers. Stress and the psychological problems represent a serious burden for adolescents with $\mathrm{AD}$ and cause a significant worsening of the patients' quality of life (QoL). The pharmacological treatment is similar to other age groups. Educational and psychological approaches should be considered in the most severe cases.

\section{Introduction}

Atopic dermatitis (AD) is a chronic inflammatory skin disease which typically affects children during the first years of life, with a prevalence around $10-30 \%{ }^{1,2}$ Recent studies have shown that in $10-20 \%$ of children with $\mathrm{AD}$, the disease persists through adolescence. ${ }^{3,4}$ In particular, few years ago the international study ISAAC Phase III estimated that, among adolescents, $\mathrm{AD}$ is present in 5-10\% in most European countries, $15-20 \%$ in UK and South America and in 0-5\% in Asia. ${ }^{5}$

Peters and colleagues ${ }^{4}$ evaluated the course of $\mathrm{AD}$ in a group of German adolescents, who had been enrolled for the ISAAC Phase II, and were able to recognize several risk factors: family history for allergic rhinitis $(\mathrm{OR}=1.6)$ and/or $\mathrm{AD}(\mathrm{OR}=2.7)$, allergic sensitization during the first years of life $(\mathrm{OR}=1.8)$, jobs at risk for allergen exposure (hairdresser, nurse and health care professionals, cleaning staff, baker) $(0 \mathrm{R}=1.4)$.

Adolescents with $\mathrm{AD}$ are rarely affected by animal protein food allergy (only $7.4 \%$ have a cow's milk or hen's egg allergy), but often show sensitization to inhalant allergens such as grass and birch pollens (44.4\% and 55.6\% respectively) and oral allergy syndrome (22\%) against plant foods.

The sex gender also influences the prevalence of $\mathrm{AD}$ : during the first 2 years of life $\mathrm{AD}$ more often affects males, ${ }^{6-8}$ but in the pubertal age and in adulthood the female sex has a higher prevalence; ${ }^{9}$ no significant differences are reported during the school age.

Ziyab and colleagues ${ }^{10}$ performed a longitudinal study in order to evaluate a relationship between variations in $\mathrm{AD}$ prevalence, gender and allergic sensitization during the first 18 years of life. Puberty seems to represent a very important period, during which a change in the disease prevalence happens $(16.3 \%$ of females and $8.3 \%$ of males, $\mathrm{P}<0.001$ ); the study results indicate that this difference might be due to an increase in girls affected by intrinsic $\mathrm{AD}$ (5.9\% females and $1.5 \%$ males, $\mathrm{P}=0.002$ ) and to a higher number of healed males ( $65.4 \%$ of males and $50 \%$ of females, $\mathrm{P}=0.04$ ). No differences were highlighted in the disease severity during puberty between males and females. Several studies evidenced that up to $30-40 \%$ of children affected by asthma, eczema and rhinitis during childhood were allergic children; the paper by Ziyab et al. ${ }^{10}$ indicates a higher prevalence of allergic sensitization for inhalant allergens (grass pollens, Alternaria alternata, Cladosporium, dog's and cat's dander) at 4, 10 and 18 years of age among male patients than in girls $(\mathrm{P}=0.024, \mathrm{P}=0.003$ and $\mathrm{P}<0.001$ respectively).

Mohrenschlager $e$ coll. ${ }^{11}$ performed a study on a population of 5-7 year-old patients and showed that girls have a higher skin $\mathrm{pH}$ and a lower hydration of the stratum corneum than boys, independently of being affected by $\mathrm{AD}$; this might cause female patients to have a higher risk of developing eczema.

Several authors highlighted that female AD patients have an important worsening of the skin condition during the pre-menstrual period, menstruations and pregnancy, suggesting that an association exists between hormonal levels and $\mathrm{AD}$ lesions. ${ }^{12,13}$ About $52 \%$ of patients
Correspondence: Giampaolo Ricci, Department of Pediatrics, University of Bologna, via Massarenti 11, Bologna, Italy

Tel. +39.051.6363075.

E-mail:giampaolo.ricci@unibo.it

Key words: atopic dermatitis, adolescence, quality of life.

Conflict of interest: the authors have no conflict of interest.

Received for publication: 31 August 2011.

Revision received: 24 October 2011.

Accepted for publication: 24 October 2011.

This work is licensed under a Creative Commons Attribution NonCommercial 3.0 License (CC BYNC 3.0).

(C) Copyright G. Ricci et al., 2012

Licensee PAGEPress, Italy

Dermatology Reports 2012; 4:e1

doi:10.4081/dr.2012.e1

with $\mathrm{AD}$ show a worsening during pregnancy, usually in the first 2 weeks of gestation; however, the mechanisms are not yet completely understood. During pregnancy a T cell switch towards a Th2-type response occurs; this phenomenon is probably due to a reduction in Deidroepiandrosterone (DHEA) and Deidroepiandrosterone-solfato (DHEA-S) levels. An increase in Th2 activity might explain the eczema worsening; it is unclear whether changes in the filaggrin expression also happen. ${ }^{14}$ Pincus et al. ${ }^{15}$ also showed the existence of an inverse association between progesterone levels during the first months of pregnancy and the risk of developing $\mathrm{AD}$ during adolescence in girls but not in boys. No association has been highlighted between maternal levels of estradiole during pregnancy and the risk of developing $\mathrm{AD}$. Experiments on mice speculate on a possible stimulating effect of estrogens on mast cell activation. DHEA might antagonize the Th2 cytokines release, but the role of testosterone and other androgens has not been clarified yet. ${ }^{16}$ DHEA-S levels in the peripheral blood increase in response to stress, chronic inflammation and immunomediated processes, but the actual role of this phenomenon has not been elucidated and no changes in the peripheral blood levels of this hormone have been detected in women affected by severe $\mathrm{AD}$.

In most cases, patients with $\mathrm{AD}$ improve or recover during childhood. However, in some cases AD persists through adulthood and is associated with the onset of allergic rhinitis and/or asthma. The risk of developing asthma in children affected by $\mathrm{AD}$ varies from $25 \%$ to $80 \%{ }^{17}$ 


\section{Clinical features}

The typical eczematous lesions appear mainly during the first two years of life with a different distribution depending on the age of the patients. During the first months of life lesions are exudative and mainly localized in the head, face (in particular forehead, cheeks, chin, with the central-face saving) and in the extensor surfaces of limbs. In older children the lesions are mainly concentrated on the flexural surfaces of the limbs, the popliteal and antecubital folds, back of hands and feet. The skin is commonly dry with lichenification and intense itch; the lips are frequently dry brittle, chapped and develop fissures. A post-inflammatory hyperpigmentation is frequently found in the region around the eyes. The evolution of the clinical feature is characterized by phases of remission of symptoms, which occur mostly during the summer months, alternating with periods of exacerbation, particularly during the autumn-winter. ${ }^{18}$ Clinical features typical of adolescence are represented by eyelid dermatitis, and the palmar and plantar juvenil dermatitis; the eczematous lesions are often localized to the neck, and in are often associated with infection by Malassezia. ${ }^{19}$ The lesions are also localized in forehead, perioral region, neck, upper chest and shoulder girdle, flexor surfaces of the legs and backs of hands.

\section{Quality of life}

The early onset, the severity of the framework, frequent relapses and chronic course make a disease with important psychological consequences that affect the quality of life (QoL) of the children and their families. ${ }^{20}$ These discomforts are accentuated if the persistence of symptoms progresses through adolescence. Affected children often present behavioral problems, mainly characterized by increased emotional dependency, anxiety, and sleep disturbances. The itching, which is one of the main symptoms of the disease, affects mood and sleep quality of patients and consequently of their family. The chronic course characterized by remission and exacerbation and the long-term treatments, negatively affects the quality of family life, both economically and psychologically, producing anxieties, frustrations, creating feelings of guilt and anger. Adolescents with AD exhibit greater vulnerability, anger, anxiety, insecurity, but few studies have been done about it.

A recent study ${ }^{21}$ study of 367 American adolescents suffering from atopic diseases has highlighted the existence of a significant association between increased levels of anxiety and the presence of allergic respiratory diseases (asthma and $\mathrm{RC}$ ) but not with the $\mathrm{AD}$; in this study it seems that $\mathrm{AD}$ affects the QoL in general terms of itching, and sleep disturbance, but it is subjectively experienced by patients as less severe than respiratory diseases.
A study by Brenninkmeijer et al. ${ }^{22}$ considered a group of 165 patients aged between 18 and 30 years who had $\mathrm{AD}$ during childhood. $\mathrm{AD}$ had a highly negative impact on patient QoL in the $48.7 \%$ of patients, with significant correlation between disease severity and QoL $(\mathrm{R}=0.518, \mathrm{P}<0.001)$. Among the problems identified, patients had experienced the need to receive clearer information about the treatment of the disease (87\%), greater empathy with the doctor (85\%), the need to deal with other patients with AD (52\%) and the need of a psychological support (68\%). Furthermore, adolescents with moderate/ severe $\mathrm{AD}$ had shown a significant delay in development of social relationships (lower number of friends, reducing output in a group) compared to healthy ones and those with mild $\mathrm{AD}$.

During high school, $70 \%$ of patients reported to be ashamed of their skin, $49.1 \%$ avoided intimate situations, $43.2 \%$ abstained from sport, 90\% reported intense itching, $69.2 \%$ sleep disturbance, fatigue $60.2 \%$ and $74.1 \%$ physical deterioration of the lesions with stress. A study by Saunes et al..$^{23}$ of Norwegian adolescents with $\mathrm{AD}$ showed a correlation between the severity of clinical feature and increased levels of psychological stress. In particular, the prevalence of psychological distress was highest in the largest age group (17-19 years). Although females were more affected by psychological stress than males, the association between $\mathrm{AD}$ and psychological distress was higher in males than females $(\mathrm{OR}=2.1$ $\mathrm{OR}=1.3$ ).

Sang Ho et al. ${ }^{24}$ evaluated the psychological characteristics of 34 patients with AD (age 1341 years) by the following questionnaire: Back Depression Inventory (BDI), State Trait Anxiety Index (STAI), Interaction anxiousness Scale (IAS), private body consciousness (PBC) and the Dermatology Life Quality Index (DLQI) and found a significant increase of all parameters of the questionnaires and a significant correlation between the parameters of the questionnaires covered and the DLQI $(\mathrm{P}<0.001)$. Among the clinical parameters the itch was significantly correlated with levels of anxiety $(\mathrm{R}=0.525, \mathrm{P}<0.05)$.

\section{Atopic dermatitis management}

The basis of therapy for the management of $\mathrm{AD}$ in adolescents are similar to those of younger child. It may be noted that the adherence to therapy, which often must be at least daily for prolonged periods, is certainly more difficult for the adolescents.

To encourage this therapeutic compliance in adolescents, a recent study ${ }^{25}$ conducted in the U.S. used short message service (sms) to the mobile phone to remember to patients the need of a daily therapy. The study showed that daily sending sms to mobile patients, led to significant improvements in patient compli- ance $(P \leq 0.001)$, their self-care $(P=0.002)$, severity $(\mathrm{P}<0.001)$ and $\mathrm{QoL}(\mathrm{P}=0.014)$. The need to create an educational and training program to educate, inform and support families with children affected by $\mathrm{AD}$ in the management of this disease originates the concept of the School of atopy, on the model of the first educational program initiated in Germany: the Berlin parental Education Programme ${ }^{26}$ based on a series of meetings between specialists and family. The Schools of atopy are differently structured, depending on different countries, although in general the standard provides, in addition to a coordinator or leader, a dermatologist, a pediatrician, an allergist and a clinical psychologist, to which other figures can be added. A study by Ricci et al. ${ }^{27}$ on a group of children with $\mathrm{AD}$ and their parents, who had joined this educational program for 3 years, showed a significant reduction in anxiety levels in parents mostly.

\section{Conclusions}

$\mathrm{AD}$ in adolescents remains a condition in which is need to investigate several aspects: while the clinical feature is well characterized, there are also risk factors that promote the persistence of $\mathrm{AD}$ from the first years of life. It is also necessary to investigate better the relationship with psychological problems, the disturbing presence of $\mathrm{AD}$ in adolescence can become, through a vicious circle, the cause of worsening of the same.

\section{References}

1. Girolomoni G, Abeni D, Masini C, et al. The epidemiology of atopic dermatitis in Italian schoolchildren. Allergy 2003:58: 420-5.

2. The International Study of Asthma and Allergy in Childhood (ISAAC) Steering Committee. Worldwide variation in the prevalence of symptoms of asthma, allergic rhinitis, and atopic eczema: ISAAC. Lancet 1998;351:1125-32.

3. Buggiani G, Ricceri F, Lotti T. Atopic dermatitis. Dermatolo Ther 2008;21:96-100.

4. Peters AS, Kellbergere J, Vogelberg C, et al. Prediction of the incidence, recurrence and persistence of stopic dermatitis in adolescence: a prospective cohort study. JACI 2010;126:590-5.

5. Williams HC. Eczema across the World: The Missing Piece of the Jigsaw Revealed. J Inves Dermatol 2011;131:12-4.

6. Asher MI,Montefort S, Bjorksten B, on behalf of the ISAAC Phase Three Study Group. Worldwide time trends in the 
prevalence of symptoms of asthma, allergic rhinoconjunctivitis, and eczema in childhood: ISAAC phases one and three repeat multicountry cross-sectional surveys. Lancet 2006;368:733-43.

7. Smidesang I, Saunes M, Storrø 0, et al.Atopic dermatitis among 2-year olds; high prevalence, but predominantly mild disease - the PACT study, Norway. Pediatr Dermatol 2008;25:13-8.

8. Dirven-Meijer PC, Glazenburg EJ, Mulder PG, et al. Prevalence of atopic dermatitis in children younger than 4 years in a demarcated area in central Netherlands: the West Veluwe Study Group. Br J Dermatol 2008;158:846-7.

9. Chen W, Mempel M, Schober W, et al. Gender difference, sex hormones, and immediate type hypersensitivity reactions. Allergy 2008;63:1418-27.

10. Ziyab AH, Raza A, Karmaus W, et al. Trends in eczema in the first 18 years of life: results from the Isle of Wight 1989 birth cohort study. Clin Exp Allergy 2010; 40.1776-84.

11. Mohrenschlager M, Schafer T, Huss-Marp $\mathrm{J}$, et al. The course of eczema in children aged 5-7 years and its relation to atopy: differences between boys and girls. $\mathrm{Br} \mathrm{J}$ Dermatol 2006;154:505-13.

12. Suhyun Cho, Hee Jung Kim, Sang Ho, et al. The Influence of Pregnancy and Menstruation on the Deterioration of Atopic Dermatitis Symptoms. Ann Derma- tol 2010;22:180-5.

13. Kemmet D, Tidman MJ. The influence of the menstrual cycle and pregnancy on atopic dermatitis. Br J Dermatol 1991;125: $59-61$.

14. Weatherhead S, Robson SC, Reynolds NJ. Eczema in pregnancy. BMJ 2007;335:1524.

15. Pincus M, Keil T, Rucke M, et al. Fetal origin of atopic dermatitis. J Allergy Clin Immunol 2009;125:273-5.

16. Ebata T, Itamura R, Aizawa H, et al. Serum sex hormone levels in adult patients with atopic dermatitis. J Dermatol 1996;23:6035.

17. Ricci G, Patrizi A, Giannetti A, et al. Does improvement management of atopic dermatitis influence the appearance of respiratory allergic diseases? A follow-up study. Clin Mol Allergy 2010;8:8.

18. Braun-Falco 0, Plewig G, Wolf $\mathrm{HH}$, et al. Dermatology 2002;501:504.

19. Darabi K, Grim Hostetler S, Bechtel MA. The role of Malassezia in atopic dermatitis affected the head and the neck of adults. $\mathrm{J}$ Am Acad Dermatol 2009;60:125-36.

20. Ricci G, Bendandi B, Bellini F, et al. Atopic dermatitis: quality of life of young Italian children and their families and correlation with severity score. Pediatr Allergy Immunol 2007;18:245-9.

21. Slattery MJ, Essex MJ. Specificity in the association of anxiety, depression and atopic disorders in a community sample of adolescents. J Psychiat Resh 2011;45:78895.

22. Brenninkmeijer EE, Legierse CM, Sillevis Smitt JH, et al. The Course of Life of Patients with Childhood Atopic Dermatitis. Pediatr Dermatol 2009;26:14-22.

23. Saunes M, Smidesang I, Holmen TL, et al. Atopic dermatitis in adolescent boys is associated with greater psychological morbidity compared with girls of the same age: the Young-HUNT study. Br J Dermatol 2007;156:283-8.

24. Sang Ho OH, Byung Gi BAE, Chang Ook PARK, et al. Association of stress with symptoms of atopic dermatitis. Acta Derm Venereol 2010;90:582-8.

25. Pena-Robichaux V, Kvedar JC, Watson AJ. Text messages as a reminder aid and educational tool in adults and adolescents with atopic dermatitis: a pilot study. Dermatol Res Pract. 2010; 2010: 894258.

26. Wenninger K, Khert R, von Rueden U, et al. Structured parent education in the management of childhood atopic dermatitis: The Berlin model. Patient Educ Couns 2000;40:253-61.

27. Ricci G, Bendandi B, Aiazzi R. Three years of Italian experience of an educational program for parents of young children affected by atopic dermatitis: improving knowledge produces lower anxiety levels in parents of children with atopic dermatitis. Pediatr Dermatol 2009;26:1-5. 